\title{
High ratio of red-to-blue LED light improves the quality of Lachenalia 'Rupert' inflorescence
}

\author{
Renata Wojciechowska ${ }^{1 *}$, Ewa Hanus-Fajerska ${ }^{1}$, Iwona Kamińska ${ }^{1}$, \\ Aleksandra Koźmińska ${ }^{1}$, Olga Dlugosz-Grochowska ${ }^{1}$, Anna Kapczyńska ${ }^{2}$
}

${ }^{1}$ Institute of Plant Biology and Biotechnology

${ }^{2}$ Department of Ornamental Plants

University of Agriculture in Krakow

29 Listopada 54, 31-425 Krakow, Poland

\begin{abstract}
The southern African geophyte Lachenalia with an enormous number of species and cultivars is nowadays a commercially important plant material. There is a need for research on the optimization of growing conditions to obtain a satisfactory visual quality of potted plants, which may boost its production on the international ornamental market. Our research can be considered as an innovative study on supplemental irradiation with various light spectra in relation to flower quality of Lachenalia spp. The main objective was to examine the usefulness of LED lighting in extending the length of the natural day to a $16 / 8 \mathrm{~h}$ photoperiod in order to control the development of Lachenalia 'Rupert' inflorescence during greenhouse cultivation in Central-European winter time. Three light treatments were applied with red $(660 \mathrm{~nm})$ and blue $(440 \mathrm{~nm})$ light in different ratios: $100 \%$ red (100/0), $90 \%$ red mixed with $10 \%$ blue $(90 / 10)$ and $80 \%$ red with $20 \%$ blue $(80 / 20)$. The PPFD at the plant leaf level was approx. $150 \mu \mathrm{mol} \mathrm{m} \mathrm{m}^{-2} \mathrm{~s}^{-1}$. The most favourable spectrum, 90/10, induced the longest inflorescences characterized by the highest stem diameter with simultaneously the highest number of florets. Additionally, blue light increased the anthocyanin content in the corolla by about $35 \%$, compared with plants exposed to $100 \%$ red light and non-irradiated ones (control plants). This first study on the wavelength ratios is aimed to increase the production quality of Lachenalia and indicates the need for continuation.
\end{abstract}

Key words: anthocyanins, dry matter, florets, growth of inflorescence

\section{INTRODUCTION}

Lachenalia J. Jacq. ex Murray is a genus of bulbous geophyte plants endemic to South Africa and Namibia. Their growth and development occur in winter as a consequence of winter rainfall in the natural habitats where the group of African geophytes is concentrated. About 110 species belonging to the genus represent the Flora of Southern Africa (FSA) (Duncan, 1996; Grace van Staden, 2003). The numerous representatives of this genus have been collected in the most important botanical gardens of the world since the time when the Cape of Good Hope was colonized in the $17^{\text {th }}$ century, but suitable species would not start to be commercially grown until the $20^{\text {th }}$ century. The first breeding schemes were focused on obtaining hybrids which could be cultivated in pots and thus produced as ornamental plants in either the United States or Europe (Baker, 1987; Niederwieser, 2004; Stropp et al., 2016). Studies on the diversity within the

*Corresponding author. 
genus have recently been receiving a lot of attention (Kleynhans et al., 2002; Reinten et al., 2011). The horticultural value of Lachenalia species derives from the interesting shapes of the leaf rosettes and appealing inflorescences with flowers of diversified colours. Moreover, the showy inflorescences remain attractive for a long time.

In northern latitudes, Lachenalia require greenhouse cultivation in order to produce flowers during winter time, and in this case bulbs are planted in autumn (Kapczyńska, 2014). However, the hours of daylight in the daily cycle get much shorter during that time. A short day would be the cause of obtaining only a small number of flowering plants because most of them require a longer photoperiod and higher light intensity than that provided by the sun in winter. Moreover, in greenhouses, lighting with high pressure sodium lamps results in elevated energy costs, thus in recent years light emitting diodes (LEDs) have been implemented as an alternative potential light source for cultivation (Currey and Lopez, 2013; Iersel and Gianino, 2017). Generally, in the supplementation of natural light, the increased proportion of blue LED light to red may diminish stem extension and enhance photosynthetic capacity due to an increase in chlorophyll content (Viršilě et al., 2017). However, many effects are determined by a given species or cultivar, plant development stage, or the tested spectrum of supplementary light (Poel and Runkle, 2017).

So far, there has been no available study concerning the effects of LED lighting on the quality parameters of Lachenalia cultivated in greenhouse conditions. The first report on the influence of light spectrum regarding this species concerns the propagation in tissue culture. Beneficial impact of blue fluorescent (FL) light on soluble carbohydrate and starch contents in bulbs formed by Lachenalia 'Rupert' explants was ascertained by Bach et al. (2015). Moreover, blue and white FL light stimulated the formation of adventitiously regenerated shoots of Rupert and Ronina cultivars, with a simultaneous increase in the total phenolic concentration (Bach et al., 2018). Phenolics are known to be synthesized in response to light quality (Ouzounis et al., 2014). The representative group of these compounds is the flavonoid family with anthocyanins as the important metabolites. These compounds perform crucial functions in plant organism and their common presence in the flower crown (or corolla tube) of numerous species increase their decorativeness, which is of great importance in the case of ornamental plants (Skowyra et al., 2014; Lou et al., 2017).

The objective of the present study was to examine the usefulness of LED supplemental lighting for controlling inflorescence development in Lachenalia 'Rupert' during greenhouse cultivation in Central-European winter time. The specific aim of the experiment was to test whether complementing red light with blue light in supplemental irradiation could improve the quality of inflorescences, and in which proportion it should be applied -10 or $20 \%$. As the control, respective material was grown under natural light (approx. 18\% blue light in spectrum). Furthermore, we hypothesised that light quality would affect the anthocyanin content in the flower corolla, which may raise the attractiveness of inflorescences. This research can be considered as an innovative study on supplemental irradiation with various light spectra in relation to flower quality of Lachenalia spp.

\section{MATERIAL AND METHODS}

\section{Plant material and growing conditions}

The study was conducted in the years 2016-2017 in an experimental greenhouse of the Agricultural University in Krakow $\left(50^{\circ} 03^{\prime} \mathrm{N}, 19^{\circ} 57^{\prime} \mathrm{E}\right)$, Poland, during Central-European winter time. The investigated plant material was the cultivar Rupert of the genus Lachenalia J. Jacq. ex Murray, from the Asparagaceae family (previously Hyacinthaceae), with darkly spotted leaves, and blooming in lilacpurple colour. Bulbs were derived from the plant collection of the Department of Ornamental Plants. The Lachenalia collection was based on bulbs previously bought from the company Afriflowers, South Africa. Bulbs of similar size (mean weight $3.3 \mathrm{~g}$ and diameter about $19 \mathrm{~mm}$ ) were planted on $21^{\text {st }}$ September 2016 into $3 \mathrm{~L}$ plastic pots, three bulbs per pot, three pots in each light treatment. Each bulb was treated as a replication. The growing substrate (Klassmann KTS-2, pH 5.8; EC $1.2 \mathrm{mS}$ $\mathrm{cm}^{-1} ; \mathrm{N} 410 \mathrm{mg} \mathrm{L}^{-1}, \mathrm{P}_{2} \mathrm{O}_{5} 160 \mathrm{mg} \mathrm{L}^{-1}, \mathrm{~K}_{2} \mathrm{O} 620 \mathrm{mg}$ $\mathrm{L}^{-1}$, Ca $1325 \mathrm{mg} \mathrm{L}^{-1}, \mathrm{Mg} 146 \mathrm{mg} \mathrm{L}^{-1}$, S $305 \mathrm{mg} \mathrm{L}^{-1}$ ) was mixed with perlite in a ratio of $3: 1 \mathrm{v} / \mathrm{v}$. The relative humidity and ambient temperature levels during the whole experiment were $49 \% \pm 3 \%$ and $18 / 15.0^{\circ} \mathrm{C} \pm 1.5^{\circ} \mathrm{C}$ day/night, respectively. The average natural solar radiation during the experiment was $211.4 \mathrm{~J} \mathrm{~m}^{-2}$ per day. Climatic data were measured and saved by a computer-controlled system which is a part of the greenhouse inventory (Netafim Comp., General Report Compartments). 


\section{Light conditions}

The light-emitting diode (LED) lighting system described in detail by Grzesiak et al. (2014) was used to provide supplemental irradiation of plants to extend the length of the natural day to a 16/8 h (day/ night) photoperiod. Three light treatments were used with red $(660 \mathrm{~nm})$ and blue $(440 \mathrm{~nm})$ lights in various ratios: $100 \%$ red (100/0); $90 \%$ red with $10 \%$ blue (90/10) and $80 \%$ red with $20 \%$ blue $(80 / 20)$. HPS lamps were not used as a control because the main goal of this study was to compare plants growing under natural light (control treatment) with those irradiated with LEDs. In each light treatment, supplementary lighting was implemented after 11 weeks ( $5^{\text {th }}$ December) when the inflorescence apexes were visible in the leaf rosettes. The photosynthetic photon flux density (PPFD) at the leaf level was approx. $150 \mu \mathrm{mol} \mathrm{m} \mathrm{m}^{-2} \mathrm{~s}^{-1}$.

\section{Growth parameters}

The following growth parameters of inflorescences were analyzed periodically until January $30^{\text {th }}, 2017$ (during 56 days of supplemental lighting, abbr. DSL): inflorescence height (from the apex to the base) after 7 DSL (Dec 13 $\left.3^{\text {th }}, 2016\right)$, inflorescence length (from the apex to the lowest floret), the number of open florets after 35 DSL (Jan $9^{\text {th }}, 2017$ ). After 56 DSL, the number of all formed florets was also counted. Stem diameter was measured with electronic callipers just under the oldest floret in the inflorescence stem. After the last growth measurements (56 DSL), inflorescence stems were harvested for chemical analyses.

\section{Biochemical analyses}

Dry matter content was determined in inflorescence stems ( $2 \mathrm{~cm}$ long fragments from the middle part of the stem under the oldest floret) and in representative leaf samples (from the middle part of the rosette of each plant). The samples $(1 \mathrm{~g})$ were dried to a constant weight at $105^{\circ} \mathrm{C}$. The percentage of dry matter was calculated according to the following formula:

$\%$ dry matter $=[$ dry weight of plant material $/$ fresh weight of plant material] $\times 100$

Anthocyanin concentration in the corolla was evaluated using HPLC analysis. Samples of $2 \mathrm{~g}$ of frozen (in $-32^{\circ} \mathrm{C}$ ) corolla tissue were homogenized in a mortar with $5 \mathrm{~mL}$ of acidified methanol $(\mathrm{POCH}$, Gliwice, Poland), centrifuged at $2700 \mathrm{~g}$ at $4{ }^{\circ} \mathrm{C}$ for 15 minutes; supernatants were filtered through $0.22 \mu \mathrm{m}$ syringe filters. Anthocyanin content was determined with the use of a Shimadzu (Tokyo,
Japan) chromatograph equipped with an LC-20AD Prominencebinarypump,DGU-20A5degasser,CTO10AS VP column oven and SPD-M20A diode array detector. Aliquots of $20 \mu \mathrm{L}$ of extracts were injected into Synergi 4u Fusion-RP $4.6 \times 25 \mathrm{~mm}$ column (Phenomenex, Torrance, USA). Elution of analytes was conducted in a gradient at a flow rate of $1 \mathrm{~mL}$ $\min ^{-1}$, where solvent A was $\mathrm{H}_{2} \mathrm{O}: \mathrm{MeOH}: \mathrm{H}_{3} \mathrm{PO}_{4}$ (1000:10:1), and solvent $\mathrm{B}$ was $\mathrm{MeOH}: \mathrm{H}_{3} \mathrm{PO}_{4}$ (1000:1). The gradient was set as follows: $1 \mathrm{~min}$. $-10 \%$ B, 20 min. $-25 \%$ B, 30 min. $-35 \%$ B, 40 min. $-45 \%$ B, 50 min. $-50 \%$ B, 60 min. $-70 \%$ B, $62 \mathrm{~min} .-100 \%$ B. Chemicals for the preparation of eluents were purchased from Sigma-Aldrich and were of HPLC gradient grade quality. Determination of anthocyanin compounds was conducted with the use of an external standard curve of cyanidin chloride (Sigma Aldrich, USA). Compounds were classified as anthocyanins by comparing absorption spectra and retention times of peaks obtained at a wavelength of $520 \mathrm{~nm}$. Then, peak areas were added up and calculated as cyanidin equivalents ( $\mu \mathrm{g}$ $\mathrm{g}^{-1} \mathrm{FW}$ ).

The laboratory analyses of dry matter and anthocyanin content were performed in quadruplicates and triplicates, respectively, within each light treatment.

\section{Statistical analysis}

Values are presented as mean \pm standard deviation. The data were analyzed with one-way ANOVA (Statistica, version 12) followed by Fisher's LSD post-hoc test. To assess the differences between the mean values of analyzed parameters, homogenous groups were determined at the probability level of $p<0.05$.

\section{RESULTS}

According to the data included in Table 1, the supplemental LED lighting did not significantly affect the height of the inflorescence stalk over the 56-day time span of light supplementation (56 DSL) when the quality of lachenalia blooming was estimated. However, when analyzing the difference in the rate of inflorescence growth during the whole vegetation period (Fig. 1), significant effects of particular light treatments were revealed. Within the 4 weeks between 7 and 35 DSL, the blue LED light, both at 10 and $20 \%$ in the emitted spectrum, inhibited stalk elongation in comparison with $100 \%$ red- and non-irradiated plants. Relative to the control, the 90/10 light significantly increased the 
Table 1. Characteristics of Lachenalia 'Rupert' inflorescence in full bloom ( 56 days of supplemental lighting, DSL) as a result of supplemental LED irradiation

\begin{tabular}{lccccc}
\hline $\begin{array}{l}\text { Light treatment } \\
\text { red/blue }\end{array}$ & $\begin{array}{c}\text { Height of inflo- } \\
\text { rescence stem } \\
(\mathrm{cm})\end{array}$ & $\begin{array}{c}\text { Stem diameter } \\
(\mathrm{mm})\end{array}$ & $\begin{array}{c}\text { Inflorescence length } \\
(\mathrm{cm})\end{array}$ & $\begin{array}{c}\text { Number of all florets } \\
\text { in inflorescence }\end{array}$ & $\begin{array}{c}\text { Floret length } \\
(\mathrm{cm})\end{array}$ \\
\hline $100 / 0$ & $45.7 \pm 2.45$ & $7.16 \pm 0.60 \mathrm{ab}$ & $12.6 \pm 1.90 \mathrm{~b}$ & $21.8 \pm 2.15 \mathrm{ab}$ & $2.8 \pm 0.11$ \\
$90 / 10$ & $47.3 \pm 2.55$ & $8.54 \pm 0.65 \mathrm{a}$ & $15.8 \pm 0.55 \mathrm{a}$ & $30.4 \pm 2.22 \mathrm{a}$ & $2.8 \pm 0.13$ \\
$80 / 20$ & $42.6 \pm 2.70$ & $7.13 \pm 0.67 \mathrm{ab}$ & $11.9 \pm 1.40 \mathrm{~b}$ & $16.3 \pm 1.45 \mathrm{~b}$ & $3.0 \pm 0.12$ \\
0 (control) & $47.3 \pm 2.65$ & $6.40 \pm 0.46 \mathrm{~b}$ & $14.9 \pm 0.61 \mathrm{ab}$ & $14.9 \pm 1.55 \mathrm{~b}$ & $2.7 \pm 0.12$ \\
\hline
\end{tabular}

Values marked with the same letters in columns do not differ significantly at $p \leq 0.05$ according to Fischer's NIR test; each data value represents mean \pm standard deviation $(n=6)$

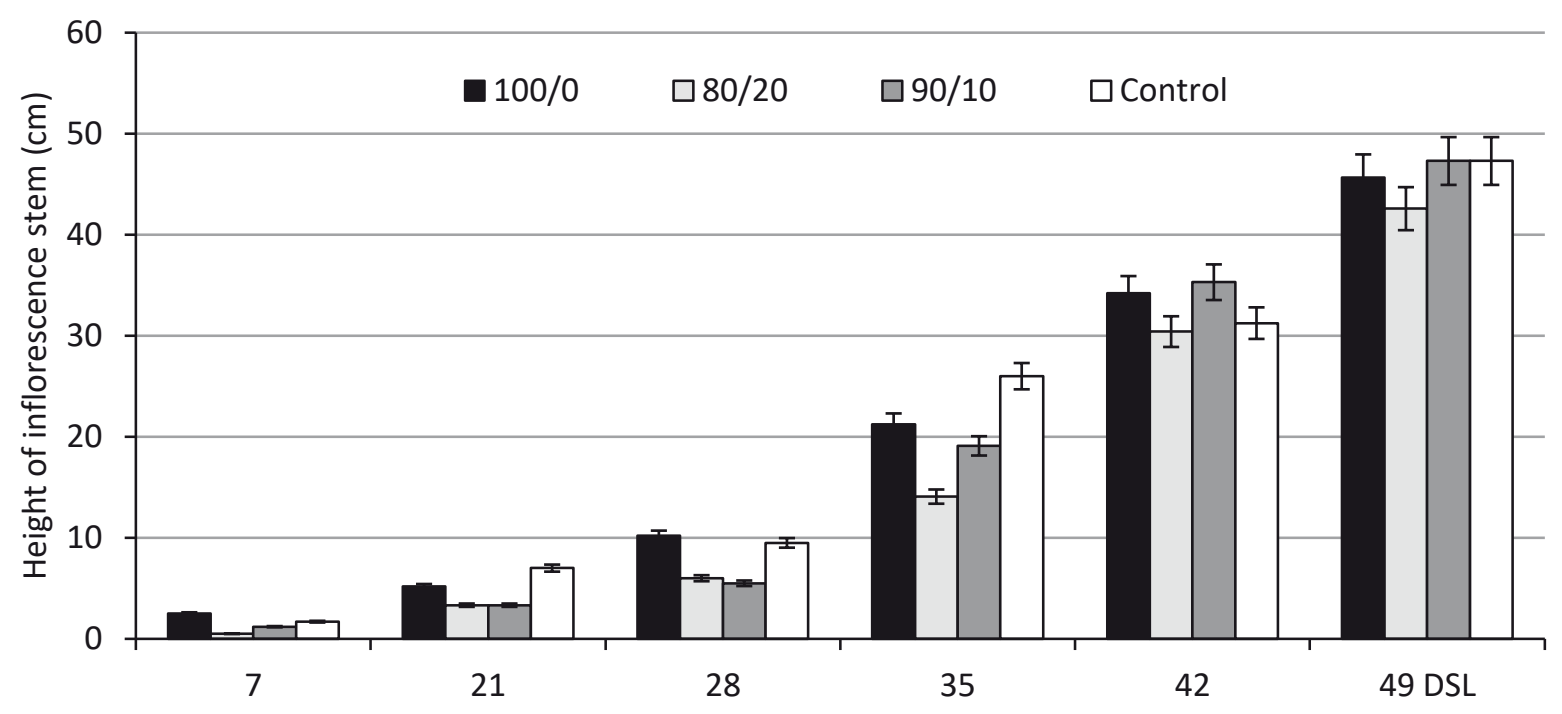

Figure 1. Changes in the length of inflorescence stem (from the apex to the base) during the growth of Lachenalia 'Rupert' after 7 to 49 days of supplemental LED lighting (DSL). The red-to-blue ratio is presented in the legend. Vertical bars represent standard deviation $(n=6)$
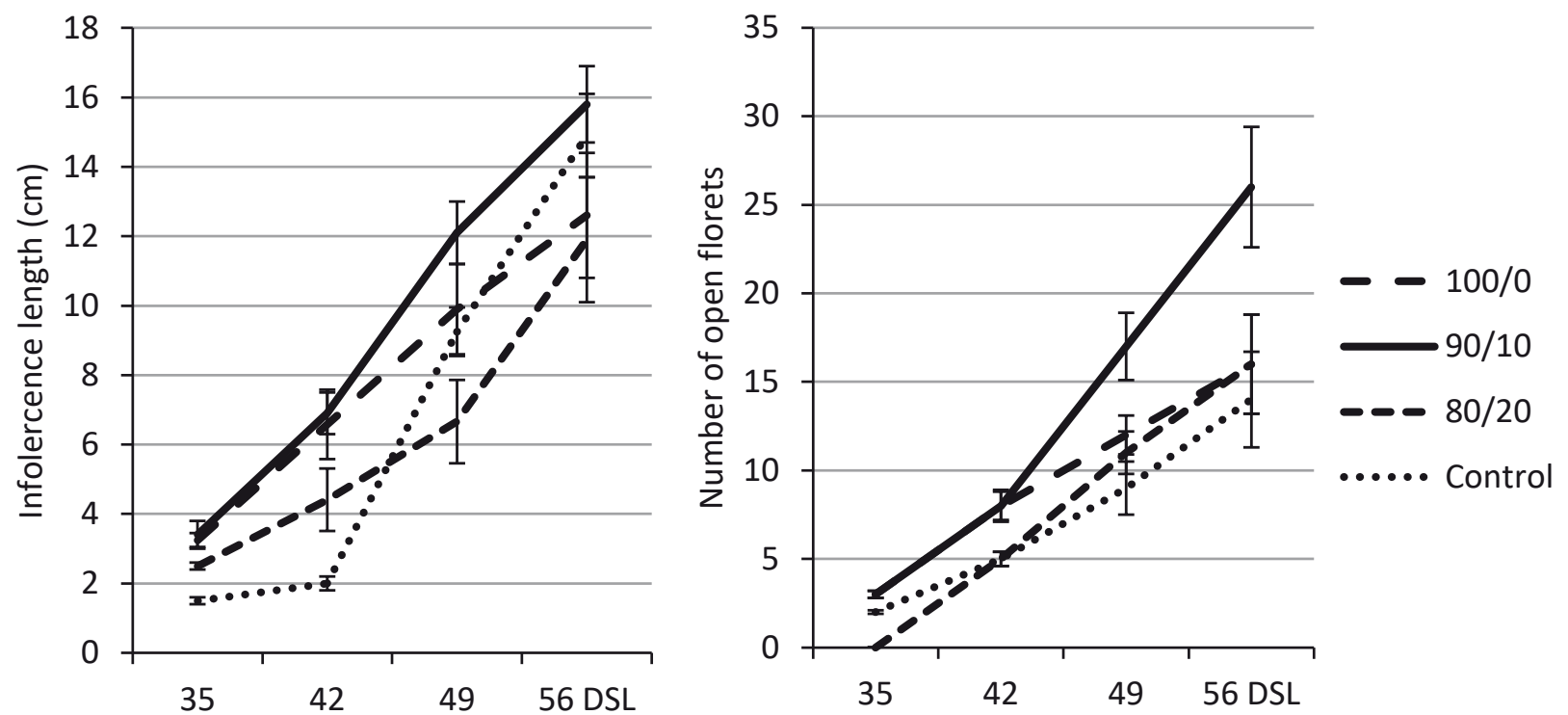

Figure 2. Inflorescence length (from the apex to the lowest floret) and the number of open florets during the growth of Lachenalia 'Rupert' in January as a result of supplemental LED lighting (DSL - days of supplemental lighting). The red-to-blue ratio is presented in the legend. Vertical bars represent standard deviation $(n=6)$ 


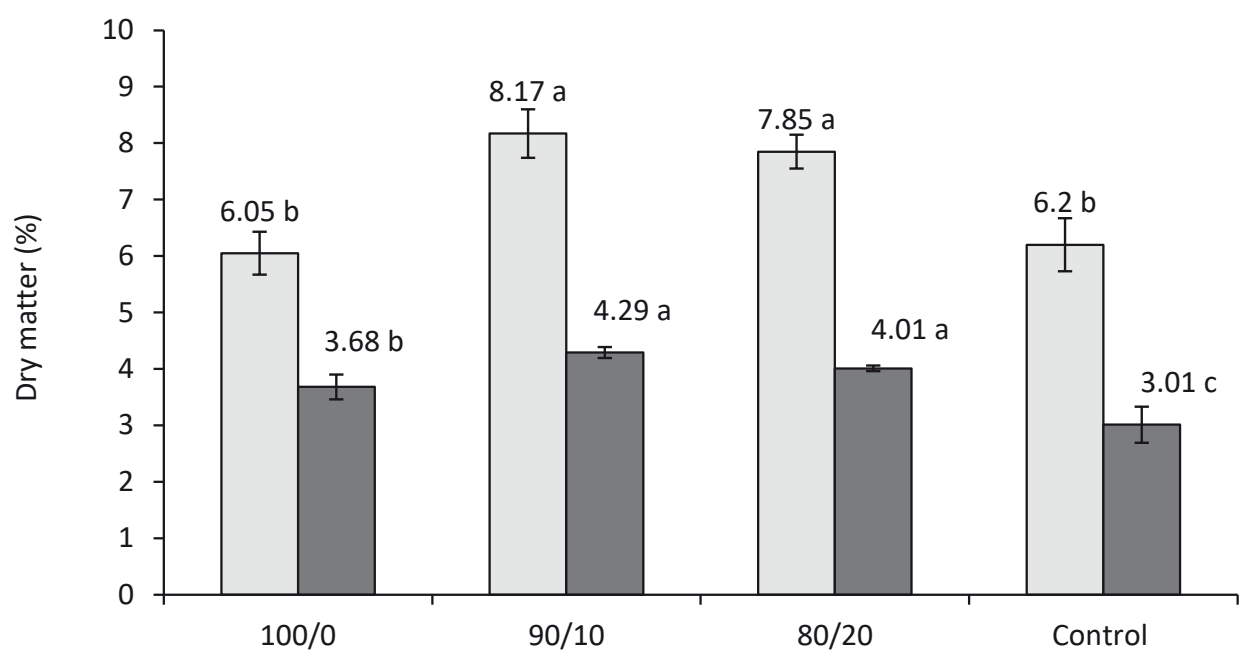

Figure 3. Effect of supplemental LED lighting on the dry matter content of inflorescence and leaves of Lachenalia 'Rupert' in full bloom (56 DSL). The red-to-blue ratio is presented under the horizontal axis. Values marked with the same letters do not differ significantly at $p<0.05$; statistical analysis was performed separately for stems (light grey bars) and leaves (dark grey bars) with Fischer's NIR test; each data value represents mean \pm standard deviation $(n=4)$

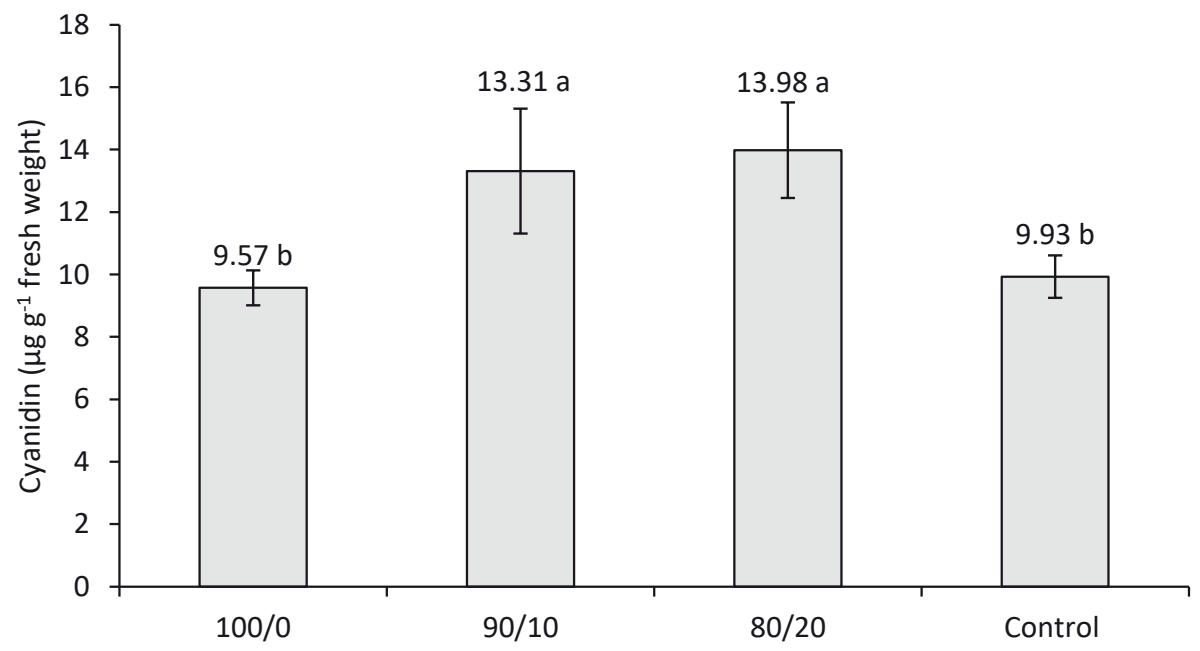

Figure 4. Effect of supplemental LED lighting on the anthocyanin content in the corolla of Lachenalia 'Rupert' florets in full blooming period (56 DSL). The red-to-blue ratio is presented under the horizontal axis. Values marked with the same letters do not differ significantly at $p<0.05$. Statistical analysis was performed with Fischer's NIR test; each data value represents mean \pm standard deviation $(n=3)$

diameter of the inflorescence stem by about $24 \%$ (Tab. 1).

Moreover, irradiation with $90 \%$ red and $10 \%$ blue light, and also with $100 \%$ red positively affected inflorescence length, resulting simultaneously in the highest number of flowers, while floret length did not depend on the type of illumination (Tab. 1). The growth of inflorescences and floret development in each treatment was gradual (Fig. 2). Between 35 and 42 DSL, the slowest growth of inflorescence was observed in the control stems and the most intensive in the treatments with a high share of red light (90 and 100\%). Moreover, in the second half of January (between 42 and 56 DSL), a very rapid increase in the number of open florets occurred under the 90/10 spectrum. There were twice as many open flowers on the inflorescence, compared with other treatments.

The dry matter content (Fig. 3), both in inflorescences and leaves, was significantly higher under the lamps which emitted blue light (90/10 and 80/20) in comparison with the control and the 'red light only' irradiation: on average by about $24 \%$ for inflorescence stems and by $20 \%$ for leaves.

Similarly, when blue light was used, the anthocyanin content in the petals of 'Rupert' inflorescences significantly increased compared with the plants treated with red light only or nonirradiated ones (Fig. 4). On average, the difference between these groups of plants was about $35 \%$. 


\section{DISCUSSION}

The main goal of this study was to analyse the quality of Lachenalia 'Rupert' inflorescence (the most decorative part of the inflorescence stalk) formed under various LED lights during winter cultivation in a greenhouse. The greater share of blue light in the spectrum (20/80) in relation to the smaller one (10/90) inhibited the length of lachenalia stalks after the $35^{\text {th }}$ day of supplemental lighting. In a greenhouse experiment with supplementary lighting, Islam et al. (2012) had achieved a reduction $(17-24 \%)$ in height in three cultivars of poinsettia when the plants were grown under LEDs with 20\% blue ( $+80 \%$ red), compared with $5 \%$ blue in an HPS (high pressure sodium lamp) spectrum. Similarly, blue light (15\% and $30 \%$ in a spectrum with red) had been shown to have an inhibitory effect on the height of Catharanthus, Celosia, Impatiens, Petunia, Tagetes, Salvia and Viola seedlings in greenhouse production (Randall and Lopez, 2014). In the cited work, the plants were more compact due to a larger stem diameter.

In our experiment, supplemental LED lighting distinctly modified the stalk diameter of Lachenalia 'Rupert'. The thickness of the inflorescence stalk is not only an important decorative feature associated with its stiffness, but it is also related to the development of vascular tissue which is a beneficial feature for flower development. In addition, the high rate of photosynthesis in the stem contributes to an increase in the pool of assimilates close to the flower buds. Compared with the control plants, the best lighting combination which significantly increased the diameter of the inflorescence stalk was $90 \%$ red $+10 \%$ blue light. At the same time, under this spectrum, the dry matter content, in both stems and leaves, was the highest. Stutte et al. (2009) had observed about 20\% more dry matter in lettuce leaves following the addition of $8-10 \%$ blue light to the spectrum, compared with the use of red light only. Considering that sugars are significant components of dry matter, it can be assumed that blue light is efficient in stimulating the process of photosynthesis. In our research with lamb's lettuce in greenhouse cultivation (Wojciechowska et al., 2013), supplemental lighting with blue and red LED light (in a ratio of 1:0.8) greatly stimulated the efficiency of the photosynthetic apparatus, compared with non-irradiated plants or illuminated with white LEDs. Considering ornamental plants, Zheng and van Labeke (2017), after an 8-week irradiation period, had shown that the use of blue light resulted in a better photosynthetic efficiency (greater maximum quantum yield $\left(\mathrm{F}_{\mathrm{v}} / \mathrm{F}_{\mathrm{m}}\right)$ and quantum efficiency $\left(\Phi_{\mathrm{PSII}}\right)$ in the leaves of Cordyline australis, Ficus benjamina and Sinningia speciosa, compared with red and white LEDs, and that this phenomenon was correlated with a lower biomass under red light illumination. By comparison, Ouzounis et al. (2014) indicated that by changing the blue-to-red ratio $(20+80 \%$ and 40 $+60 \%$, respectively) the stomatal conductance in the leaves of Rosa, Chrysanthemum and Campanula increased, although changes in net photosynthesis were not observed. Our results suggest that further research on the photosynthetic parameters in Lachenalia leaves is needed, especially because sugars are among the main signalling molecules related to flowering (Matsoukas, 2017).

The rate of floret development can be related to a larger inflow of assimilates from the stems and leaves of the plant. Therefore, the 90/10 spectrum could be considered as the most favourable to the stimulation of the development of florets in Lachenalia 'Rupert'. It is interesting why, in the case of the 80/20 spectrum, despite the high level of dry matter in the stalks and leaves (close to that of 90/10), inflorescence length was smaller with a smaller number of florets, similar to the control. A greater ratio of red-to-blue light expected to be more effective in stimulating floral signal transduction via phytochromes, which mediate mainly via red/far-red light perception (Matsoukas, 2017). This issue requires further research.

Supplemental LED lighting did not influence the length of the corolla. Kapczyńska (2014) had shown that irrespective of the time of planting bulbs (cultivated from October to January under natural irradiation only), the length of florets of Lachenalia 'Rupert' ranged from 2.8 to $2.9 \mathrm{~cm}$. Quite similar values were obtained in the present study; therefore, this trait of the cultivar Rupert seems to be relatively constant.

An important feature of Lachenalia plants in terms of their decorativeness is the coloration of their florets, which is related to the anthocyanin content. Total anthocyanins in lettuce 'Outredgeous' were over twice as high in the presence of blue light $(8-10 \%$ in spectrum) compared with red alone (Stutte et al., 2009). The increase in the level of phenolic compounds in plant tissues results from the activation of crucial enzymes involved in the phenylpropanoid pathway (phenylalanineammonia-lyase and chalcone synthase) by blue light (Długosz-Grochowska et al., 2016). Recently, many studies on leafy vegetables have shown 
a positive effect of blue light (460-430 nm) or UVA $(365-390 \mathrm{~nm})$ on anthocyanin content, essential for improved nutritional quality (Samuolieně et al., 2017). Our results indicate a potential of LED supplemental irradiation including blue light for improving the coloration of flowers of ornamental plants in greenhouse production. So far, the research and practical applications with the use of LED lighting have been focused on the photoperiodic aspects of flowering regulation in photoperiodsensitive plants (Viršilě et al., 2017). In the context of ornamental plants, light is not only a source of energy or stimulus but also an architect of desirable shape and colours.

Taking into consideration the value of the presented results, further studies on LED supplemental lighting of Lachenalia plants are needed. We expect that LED lighting should improve bulblet development and affect favourably the quality of whole Lachenalia plants in the subsequent growing season. A suitable light spectrum of supplemental irradiation is of great importance for improving propagation and can thus contribute to increasing the introduction of Lachenalia cultivars into the world's horticultural market.

\section{CONCLUSIONS}

1. LED illumination that complemented the natural day during Central-European winter improved the quality of Lachenalia 'Rupert' inflorescence. However, this effect was related to the spectral composition of the emitted light.

2. The addition of blue light (10 and 20\%) to red (90 and $80 \%$ ) in the spectrum significantly increased the amounts of (1) dry matter in the inflorescence stems and leaves as well as (2) anthocyanins in the petals of florets, compared with the use of red light only (100\%) and the control plants (under natural light only).

3. Higher proportion of red-to-blue light (9:1) improved the decorativeness of blooming Lachenalia 'Rupert' to the greatest extent in terms of inflorescence height and diameter, and the number of florets formed.

\section{FUNDING}

This work was supported by the Ministry of Science and Higher Education in Poland (DS 3504/2017).

\section{AUTHOR CONTRIBUTIONS}

R.W., E.H.-F., A. Kapczyńska - study conception and design; I.K., A. Koźmińska, R.W. - acquisition of data; I.K., A. Koźmińska, O.D.-G., R.W. analyses and interpretation of data; R.W., E.H.-F. manuscript writing; A. Kapczyńska, I.K. - critical revision.

\section{CONFLICT OF INTEREST}

Authors declare no conflict of interest.

\section{REFERENCES}

Bach A., KapCZyŃska A., DziUrka K., Dziurka M, 2015. Phenolic compounds and carbohydrates in relation to bulb formation in Lachenalia 'Ronina' and 'Rupert' in vitro cultures under different lighting environments. Sci. Hortic. 188, 23-29.

Bach A., KapczyŃsKa A., DziUrka K., DziUrka M., 2018. The importance of applied light quality on the process of shoot organogenesis and production of phenolics and carbohydrates in Lachenalia sp. cultures in vitro. S. Afr. J. Bot. 114, 14-19.

BAKER W.F., 1987. Five more species of Lachenalia (Liliaceae - Hyacynthoideae) four from the Cape province and one from southern west Africa/Namibia. S. Afr. J. Bot. 53(2), 166-172.

Currey C.J., Lopez R.G., 2013. Cuttings of impatiens, pelargonium and petunia propagated under lightemitting diodes and high pressure sodium lamps have comparable growth, morphology, gas exchange, and post-transplant performance. HortScience 48, 428-434.

DŁugosz-Grochowska O., KoŁton A., WojciechowSKA R., 2016. Modifying folate and polyphenol concentrations in Lamb's lettuce by the use of LED supplemental lighting during cultivation in greenhouses. J. Funct. Foods 26, 228-237.

DuncaN G.D., 1996. Four new species and one subspecies of Lachenalia (Hiacynthaceae) from arid areas of South Africa. Bothalia 26, 1-9.

Grace O.M., van Staden J., 2003. A horticultural history of Lachenalia (Hyacinthaceae). S. Afr. J. Sci. 99, 526-531.

GrZESIAK W., ŻUPNiK M., WoJCIECHOWSKA R., 2014. Praktyczna realizacja wielostanowiskowego programowalnego systemu doświetlania roślin zbudowanego w oparciu o technologie SSL LED [Practical implementation of the programmable plant irradiation system, with multiple research stations, based on SSL LED technology]. Prace Instytutu Elektrotechniki 267, 97-106.

IERSEL M.W., Gianino D., 2017. An adaptative control approach for light-emitting diode lights can reduce the energy costs of supplemental lighting in greenhouses. HortScience 52(1), 72-77. 
Islam M., Kuwar G., Clarke J.L., Blystad D.R., Gislerød H.R., Olsen J.E., Torre S., 2012. Artificial light from light emitting diodes (LEDs) with a high portion of blue light results in shorter poinsettias compared to high pressure sodium (HPS) lamps. Sci. Hortic. 147, 136-143.

KAPCZYŃSKA A., 2014. Effect of planting term on growth and flowering of two cultivars of Lachenalia produced in a greenhouse as potting plants during winter months. Hortic. Res. 22(1), 29-34.

Kleynhans R., Niederwieser J.G., Hancke F.L., 2002. Lachenalia: Development and commercialization of a new flower bulb crop. Acta Hortic. 570, 81-85.

Lou Q., Wang L., LiU H., LiU Y., 2017. Anthocyanin profiles in flowers of grape hyacinth. Molecules 22, 688.

MatsouKas I.G., 2017. Crosstalk between photoreceptor and sugar signaling modulates floral signal transduction. Front. Physiol. 8, 382.

Niederwieser J.G., 2004. Role of biotechnology in the development and production of Lachenalia and Ornithogalum cultivars in South Africa. S. Afr. J. Bot. 70(1), 47-51.

Ouzounis T., Frette X., Rosenqvist E., Ottosen C.O., 2014. Spectral effects of supplementary lighting on the secondary metabolites in roses, chrysanthemums, and campanulas. Plant Physiol.171, 1491-1499.

Poel B.R., Runkle E.S., 2017. Spectral effects of supplemental greenhouse radiation on growth and flowering of annual bedding plants and vegetable transplants. HortScience 52(9), 1221-1228.

Randall W.C., Lopez R.G., 2014. Comparison of supplemental lighting from high-pressure sodium lamps and light-emitting diodes during bedding plant seedling production. HortScience 49(5), 589-595.

Reinten E.Y., Cotzee J.H., van Wyk B.E., 2011. The potential of South African indigenous plants for the international cut flower trade. S. Afr. J. Bot. 77, 934946.

Samuolieně G., Brazaitytě A., VAštakaitě V., 2017. Light-emitting diodes (LEDs) for improved nutritional quality. In: Light Emitting Diodes for Agriculture. S. Dutta Gupta (Ed.), Springer Nature, Singapore, 149-190.

Skowyra M., Calvo M.I., Gallego M.G., Azman N.A.M., Almajano M.P., 2014. Characterization of phytochemicals in petals of different colours from Viola $\times$ wittrockiana Gams. and their correlation with antioxidant activity. J. Agric. Sci. 6(9), 93-105.

Stropp J., Ladle R.J., Malhado A.C.M., Hortal J., Gaffuri J., Memperley W.H., et AL., 2016. Mapping ignorance: 300 years of collecting plants in Africa. Glob. Ecol. Biogeogr. 25, 1085-1096.

Stutte G.W., Edney S., Skerritt T., 2009. Photoregulation of bioprotectant content of red leaf lettuce with light-emitting diodes. HortScience 44(1), 79-82.

VIrŠILĚ A., Olle M., DuChOVsKis P., 2017. LED lighting in horticulture. In: Light emitting diodes for agriculture. Dutta Gupta S. (Ed.), Springer Nature, Singapore, 113-147.

Wojciechowska R., KoŁton A., DŁugoszGrochowsKa O., ŻupniK M., GrZesiaK W., 2013. The effect of LED lighting on photosynthetic parameters and weight of lamb`s lettuce (Valerianella locusta). Folia Hort. 25(1), 41-47.

ZHENG L., vAN LABEKE M.C., 2017. Long-term effects of red- and blue-light emitting diodes on leaf anatomy and photosynthetic efficiency of three ornamental pot plants. Front. Plant Sci. 8, 917.

Received December 12, 2018; accepted January 24, 2019 